\title{
CAMBIO DE USO DEL SUELO EN LA CUENCA DEL RÍO CLARO, REGIÓN DEL BIOBÍO, EN LOS AÑOS 1986, 2001 Y 2016
}

\section{LAND USE CHANGE IN THE CLARO RIVER BASIN, BIOBÍO REGION, IN THE YEARS 1986, 2001 AND 2016}

Franco Cuevas C*

Walter Inaipil* *

RESUMEN: La cuenca del Río Claro, ubicada en la región del Biobío, Chile, experimentó entre los años 1986 a 2016 importantes transformaciones en la distribución de sus principales coberturas de suelo y las formas en que interactúa el paisaje, registrando en tal periodo un aumento significativo en la superficie de plantación forestal, una pérdida sistemática del bosque nativo e importantes transformaciones en el suelo agrícola, urbano y matorrales.

El objetivo de esta investigación es analizar los diferentes cambios de cobertura de suelo ocurridos y sus procesos predominantes en los años 1986, 2001 y 2016. Mediante la utilización de imágenes satelitales, matriz de transición e indicadores de porcentaje de cambio, se muestra una asociación entre las principales transformaciones del paisaje y su relación con los modelos agrícola y forestal en el territorio. En concordancia, fue posible determinar, en un inicio, transformaciones del paisaje asociadas a un fuerte incentivo agropecuario, mientras que, a posterior, un fuerte incentivo a la forestación. Todo a su vez, asociado a cambios en las métricas del paisaje y el uso del suelo.

Palabras clave: Cobertura de suelo, dinámica del paisaje, Bosque nativo, plantaciones forestales. 
ABSTRACT: The Rio Claro basin, located in the Bio Bio region of Chile, underwent major changes in the distribution of its main land cover and the ways in which the landscape interacts, between 1986 and 2016. During this period, there was a significant increase in the area of forest plantations, a systematic loss of native forest and major changes in agricultural and urban land, as well as scrubland.

The objective of this research is to analyze the different changes in land cover that occurred and their predominant processes in the years 1986, 2001 and 2016, respectively. Using satellite images, transition matrix and percentage change indicators, an association is shown between the main landscape transformations and their relationship with agricultural and forestry models in the territory. Accordingly, it was possible to determine, at the beginning, landscape transformations associated with a strong agricultural incentive, whereas, later, a strong incentive to forestation. All in turn, these linked to changes in landscape metrics and land use.

Key words: Land cover, landscape dynamics, native forest, forest plantation.

Recibido: 01.10.19 Aceptado: 04.02.20

\section{INTRODUCCIÓN}

La cobertura y uso del suelo son dos de los elementos que, a través del tiempo, mejor evidencian la transformación de la superficie terrestre por parte de la acción humana (Reyes et al., 2006, p. 27), tal acción, en función de cubrir sus necesidades ha transformado directamente alrededor de la mitad de la superficie terrestre (Hooke et al., 2012). A escala global, se calcula que entre los años 1700 y 1992, 1.621 millones de hectáreas fueron habilitadas para la agricultura, de ellas 885 millones correspondían a bosques, 565 millones a sabana, praderas y estepa, 150 millones a matorrales y 21 millones a tundras y desiertos (Ramankutty y Foley, 1999). En la mayoría de los países, el principal cambio de cobertura de suelo, en una perspectiva extendida en el tiempo, es la conversión de superficie forestal a cobertura y uso agrícola (Barbier et al., 2010)
El estudio y comprensión de los fenómenos que modifican los ecosistemas terrestres resulta un tema de interés global, siendo este establecido como una prioridad en la evaluación ecosistémica del milenio ONU, 2010, citado en Sotelo-Caro et al. (2015). En específico, la profundización en la comprensión de las causas directas y subyacentes que promueven los cambios en el uso de suelo, haciendo énfasis en la evaluación de las tendencias actuales y futuras de la transformación en las coberturas de suelo Galicia et al. 2014, citado en Sahagún y Reyes (2018).

En el último siglo, las transformaciones asociadas a la actividad humana han modificado las características de la superficie terrestre y la composición atmosférica, en particular a través de la conversión de tierras a gran escala, siendo el cambio de uso de suelo considerado como la primera causa de alteración del suelo (Foley et al., 2005), citado en (Aguayo et al., 2009). 
Además, autores como Sitch et al. (2015), asocian estos cambios a procesos de disminución de la biodiversidad. Dichos cambios generalmente se ha considerado un problema ambiental local. No obstante, hoy en día se ha convertido en una problemática de importancia mundial (Foley et al., 2005).

La creciente demanda de tierra para producir bienes y servicios representa la más importante interacción del sistema tierra/hombre. El uso humano de la tierra está alterando la estructura y funcionamiento de los ecosistemas, a la par que altera la relación entre los ecosistemas y su interacción con la atmósfera, los sistemas acuáticos y con la tierra circundante (Vitousek et al., 1997).

En Chile, autores como Lara et al. (1989), Pauchard et al. (2006), Echeverría et al. (2006), Altamirano et al. (2007), Aguayo et al. (2009), etc. o instituciones como la Corporación Nacional Forestal -CONAFy la Comisión Nacional de Medio Ambiente -CONAMA-, dan cuenta de las transformaciones del paisaje a escala local y regional y exploran sus consecuencias ecológicas y sociales. Estos estudios muestran que las principales causas de transformación del paisaje en el Centro y Sur del país fueron, en un inicio, la habilitación de terrenos para la agricultura y, posteriormente, la expansión de las plantaciones forestales incentivadas por un fuerte subsidio estatal (Aguayo, et al., 2009, 3631.

El presente trabajo apunta a evaluar la dinámica espaciotemporal de los cambios en la cobertura de suelo en la cuenca del río Claro, especialmente aquellas relacionadas a las métricas del paisaje, estableciendo como una unidad de estudio la cuenca hidrográfica.

\section{MÉTODO \\ ÁREA DE ESTUDIO}

El área de estudio se ubica en la cuenca del río Claro, región del Biobío, Chile, la cual se extiende entre los $37^{\circ} 00^{\prime}-37^{\circ} 15^{\prime} \mathrm{S}$ y los $72^{\circ} 30^{\prime}-72^{\circ} 45^{\prime} \mathrm{W}$ y posee una superficie de 90.303 hectáreas. Administrativamente se inserta entre las comunas de Cabrero y Yumbel con 70.052 hectáreas. 186,3\% de la cuencal y las comunas de La Florida, San Rosendo, Quillón, Yungay con 20.307 hectáreas 113,7\% de la cuenca). Climatológicamente, la cuenca corresponde a una zona del secano interior a sotavento de la cordillera de la costa, con precipitaciones anuales del orden de los 952 mm (Inzunza, 2010).

Geológicamente la cuenca se ubica en una zona de contacto entre dos unidades morfoestructurales; El borde oriental de la cordillera de la costa y el extremo occidental de la depresión intermedia situada en el río Laja (González et al., 1999). A la vez que dicha cuenca se compone de suelos tipo llg (Dioritas y Monzodioritas), Cpg (Granitos y granodioritas), Qf (Depósitos fluviales y Q3ar Idepósitos de avalancha volcánica asociadas al colapso parcial del volcán Laja (SERNAGEOMIN, 2003).

\section{FUENTES DE INFORMACIÓN}

Se utilizaron imágenes Landsat con la combinación de bandas 5, 7 y 8 de los años 1986, 2001 y 2016, además de un modelo de elevación digital (DEM) con resolución espacial de 30 m (Shutle Radar Topography Mission SRTM, ASTER GDEM). Las imágenes fueron descargadas desde la plataforma de información satelital de Science for a Changing world del USGS. Para efectos de subsanar nubosidad se consideró condición de verano con cobertura total de la cuenca. 


\section{TÉCNICAS}

La investigación se desarrolló bajo la metodología propuesta por León-Muñoz et al. (2017), utilizando los softwares ArcGIS 10.5, Envi 4.7 e IDRISI Selva. En primera instancia, las imágenes fueron corregidas geométrica y radiométricamente utilizando el software Envi 4.7, obteniendo también la clasificación de las distintas coberturas de suelo para cada intervalo de tiempo, para ello se utilizó la clasificación de coberturas propuesta por CONAF et al. (1999), del Mapa de recursos de vegetacionales de Chile.

Por medio de una matriz de confusión realizada con el software ArcGIS 10.5 se obtuvo una confianza para cada imagen del 91\% para el año 1986166 puntos de validación), un 68\% en 2001 (109 puntos de validación) y $83 \%$ en 2016 (144 puntos de validación).

Para observar los cambios de coberturas de suelo (LUC), se utilizó el software IDRISI Selva, con la aplicación Land Change Modeler propuesto por Eatsman (2006), con el cual se analizaron los principales cambios de coberturas de suelo para los distintos años, generando un mapa de procesos predominantes de cambio según el modelo propuesto por FAO (2002), citado en Echeverria et al. (2006) el cual considera además la tasa de cambio según la fórmula expuesta a continuación:

$$
\mathrm{P}=\frac{100}{\mathrm{t}_{2}-\mathrm{t}_{1}} \ln \frac{\mathrm{S}_{2}}{\mathrm{~S}_{1}}
$$

donde S1 y S2 corresponden a la superficie en el tiempo $\nmid 1$ y $\nmid 2$, respectivamente, y $P$ es el porcentaje de cambio por año.
Posteriormente, se cuantificó el porcentaje de cambio de uso de suelo, usando una matriz de transición que "consiste en una tabla simétrica de doble entrada en cuyos ejes se presentan las coberturas del suelo y en cada celda la superficie de las áreas que experimentaron cambios. Las celdas situadas en la diagonal de la matriz contienen la superficie de aquellas áreas que no experimentaron cambios durante el período" (Aguayo et al. 2009, p. 5), siendo la matriz de transición construida mediante álgebra de mapas.

\section{RESULTADOS}

El análisis de datos de la matriz de transición reveló que alrededor del $47 \%$ de la cuenca del rio Claro ha sufrido modificación en casi la totalidad de las coberturas de suelo (Figura 1).

Las coberturas que registraron mayores cambios corresponden a plantaciones forestales, suelos agrícolas, matorrales y bosque nativo. De este modo, los suelos agrícolas registran importantes pérdidas de superficie, mientras que las plantaciones forestales registraron un aumento significativo del 598\%. De manera contraria, el bosque nativo registró una pérdida del 90\% de superficie, seguido en la misma línea por una pérdida del $41 \%$ de matorrales y de manera contraria, un aumento del $272 \%$ en los suelos urbanos. 


\begin{tabular}{|c|c|c|c|c|c|c|c|c|c|c|}
\hline \multicolumn{11}{|c|}{ Aflo 1986} \\
\hline \multirow{10}{*}{ 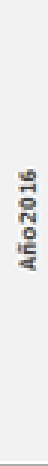 } & $\begin{array}{c}\text { Coberturas de } \\
\text { suelo }\end{array}$ & $\begin{array}{l}\text { Bosque } \\
\text { nativo }\end{array}$ & $\begin{array}{c}\text { Plantación } \\
\text { forestal }\end{array}$ & Agricultura & Matorral & $\begin{array}{l}\text { Suelo } \\
\text { urbano }\end{array}$ & Humedal & $\begin{array}{c}\text { Suelo } \\
\text { descubierto }\end{array}$ & Agua & Total 2016 \\
\hline & Bosque nativo & 338 & 0 & 0 & 0 & 0 & 1 & 0 & & 339 \\
\hline & $\begin{array}{c}\text { Plantación } \\
\text { forestal }\end{array}$ & 3876 & 5742 & 17826 & 12095 & $\mathbf{0}$ & 2 & 686 & 2 & 40256 \\
\hline & Agricultura & 893 & 0 & 27873 & 0 & 0 & 53 & 871 & 2 & 29692 \\
\hline & Matorral & 410 & 0 & 3173 & 13576 & $\mathbf{0}$ & 78 & 854 & $\mathbf{0}$ & 18091 \\
\hline & Suelo urbano & 22 & 25 & 953 & 421 & 159 & 0 & 132 & 0 & 1712 \\
\hline & Humedal & 1 & 0 & $\mathbf{0}$ & $\mathbf{0}$ & $\mathbf{0}$ & 3 & 0 & $\mathbf{0}$ & 4 \\
\hline & $\begin{array}{c}\text { Suelo } \\
\text { descubierto }\end{array}$ & 1 & 0 & $\mathbf{0}$ & 0 & $\mathbf{0}$ & $\mathbf{0}$ & 183 & $\mathbf{0}$ & 184 \\
\hline & Aguas & 0 & 0 & 0 & 0 & 0 & 1 & 9 & 15 & 25 \\
\hline & Total 1986 & 5541 & 5767 & 49825 & 26092 & 159 & 165 & 2735 & 19 & 90303 \\
\hline
\end{tabular}

Figura 1. Matriz de transición. La suma de las filas y columnas corresponde al área total en hectáreas de cada cobertura de suelo en los años 1986 y 2016, respectivamente. La lectura de los valores en el sentido de las columnas, indica el cambio de cobertura de suelo en 1986 y 2016 ; así, por ejemplo, 3.876 hectáreas de bosque nativo de un total de 5.541 hectáreas existentes en el año 1986 fueron convertidas en plantación forestal para el año 2016. Los valores diagonales indican las superficies que no experimentaron cambios en tal periodo.

Fuente: Elaboración propia.

De este modo, es posible evidenciar un aumento en la superficie de plantaciones forestales, que en 1986 se concentraban en parches ubicados en el centro de la cuenca, específicamente en las cercanías de las localidades de Las Tocas, Coihue Bajo, Paredones, General Cruz, Los Caulles y Lomas de Angol. Además de parches ubicados en la punta Sureste de la cuenca, en las localidades de La Higuera, Tricahue, alrededores de Cabrero y el Progreso.

Ya en el año 2016 dichos parches se extendieron en casi la totalidad de la cueca (Figura 2), exceptuando alrededores a los principales centros poblados, los que, en tal año, conservan actividades agrícolas, además de terrenos cubiertos por humedales y los márgenes cercanos a los principales cuerpos hídricos de la cuenca.

De la misma forma, es posible observar el crecimiento de los suelos urbanos (Figura 2), principalmente en los asentamientos de Cabrero, Yumbel y Monte Águila. 


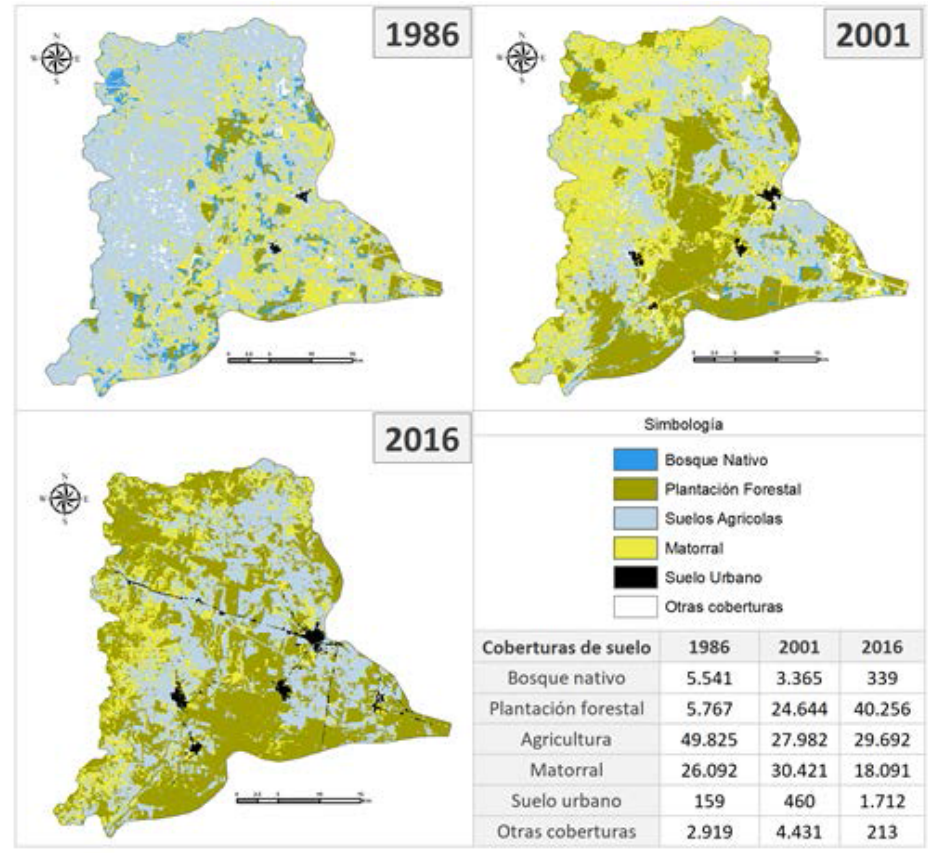

Figura 2. Dinámica de uso de suelo en los años 1986, 2001 y 2016. (Para mejor visualización, la imagen se muestra configurada en el formato "Majority for discrete data), eximiendo superficies menores a 50 hectáreas. Por otra parte, la categoría otras coberturas corresponde a la suma de las cuberturas de Humedal, agua y suelos descubiertos.

\section{PLANTACIONES FORESTALES}

Registraron un aumento de $700 \%$, pasando de las 5.767 hectáreas en 2001 a las 40.256 hectáreas en 2016, con una tasa de cambio de 13. Este aumento significativo resulta a costa de la pérdida de 17.826 hectáreas de suelos agrícolas (44\% de ganancia), 12.095 hectáreas de matorrales $(30 \%$ de ganancia) y 3.876 hectáreas de bosque nativo $110 \%$ de ganancia) y de 686 hectáreas de suelos descubiertos (2\% de ganancia). En menor medida, las plantaciones forestales sufren algunas a costa de los suelos urbano que ganan 25 hectáreas, lo que representa un 0,4\% de la superficie forestal en 1986.

Respecto a la distribución de las plantaciones forestales, es posible observar (Figura 2) que, en 1986, éstas se distribuían en pequeños parches ubicados en el margen Sureste y Centro de la cuenca, mientras que en 2016 cubren casi la totalidad de la cuenca, exceptuando las zonas centrales próximas a asentamientos humanos donde perduras suelos agrícolas y de matorrales.

\section{SUELOS AGRÍCOLAS}

Registraron una pérdida del $73 \%$ de su superficie, pasando de 49.825 hectáreas en 1986 a 29.692 hectáreas en 2001 , lo que representa una tasa de cambio de -3.5. Esta reducción posee un ligero aumento entre los años 2001 a 2016 (Figura 3), con un incremento del $6 \%$, pasando de las 27.982 hectáreas en 2001 a las 29.692 hectáreas en 2016, lo que representa una tasa de cambio positiva de 0,4.

De manera global, de entre las pérdidas registradas por el suelo agrícola, unas 17.826 hectáreas ocurren a costa de plantaciones forestales (36\% de pérdida), 3.173 hectáreas a costa de matorrales $16 \%$ de pérdida) y 953 hectáreas a costa de suelos urbanos (2\% de pérdida). 


\section{MATORRALES}

Registró una pérdida del $62 \%$ de su superficie, pasando de 26.092 hectáreas en 1986 a 18.091 hectáreas en 2016 (Figura 3), con una tasa de cambio de -2.4. De esta pérdida, no obstante, se observa que entre los años 2001 a 2016, los matorrales aumentan un $17 \%$ su superficie, ganando 4.329 hectáreas, de las cuales el $31 \%$ ocurre a costa de los suelos agrícolas y en menor medida del bosque nativo. En tal periodo la tasa de cambio se registra positiva en 2.3.

De manera contraria, las pérdidas registradas por el matorral ocurren en un $46 \%$ a costa de plantaciones forestales, con 12.095 hectáreas perdidas y un $2 \%$ a costa de suelos urbanos con una pérdida de 421 hectáreas.

\section{BOSQUE NATIVO}

Entre 1986 y 2016 fue posible cuantificar una pérdida de 5.202 hectáreas de bosque nativo (Figura 3), lo que representa una disminución de $1639 \%$ de la superficie total en 1986. Del total registrado, 3.876 hectáreas fueron convertidas en plantaciones forestales $(70 \%$ de pérdida), resultado concordante con el aumento significativo de las plantaciones forestales en tal periodo. Dicha expansión de plantaciones forestales es dada en muchos casos por la sustitución del bosque nativo en una etapa inicial, además de la implementación del DL 701, tal como menciona Donoso y
Otero (2005, p. 23), donde ocurrieron procesos como el descrito a continuación: "Jurídicamente en el año 1998 se prohibió la sustitución de cualquier bosque nativo según la Ley 19.561. No obstante, la pérdida más importante de bosque nativo entre la región del Maule y el Biobío, aconteció en una etapa anterior y ocurrió en parte por la habilitación para terrenos agrícolas, construcción de viviendas para colonos extranjeros, minería y fundiciones, por lo que hacer desaparecer el bosque era considerado en aquella época como natural e inevitable".

Por su parte, además de las pérdidas ocurridas a manos de las plantaciones forestales, otras 893 hectáreas fueron convertidas en suelos agrícolas (16\% de pérdida) y 410 hectáreas ganados por la superficie de matorral $17 \%$ de pérdida).

\section{ÁREAS URBANAS}

Las áreas urbanas registraron un aumento 1.553 hectáreas, pasando de 159 hectáreas en 1986 a 1712 hectáreas en 2016, registrando un aumento significativo del 1077\%, lo que representa una tasa de cambio de 15.9, de este aumento, el crecimiento más importante ocurre entre los años 2001 a 2016, con un aumento del $272 \%$ frente al aumento de $189 \%$ registrado entre los años 1896 a 2001.

De este aumento, 953 hectáreas son ganadas a los suelos agrícolas (56\% de ganancia), 421 hectáreas a zonas cubiertas por matorrales (25\% de ganancia) y 132 hectáreas a suelos descubiertos (8\%de ganancia). 


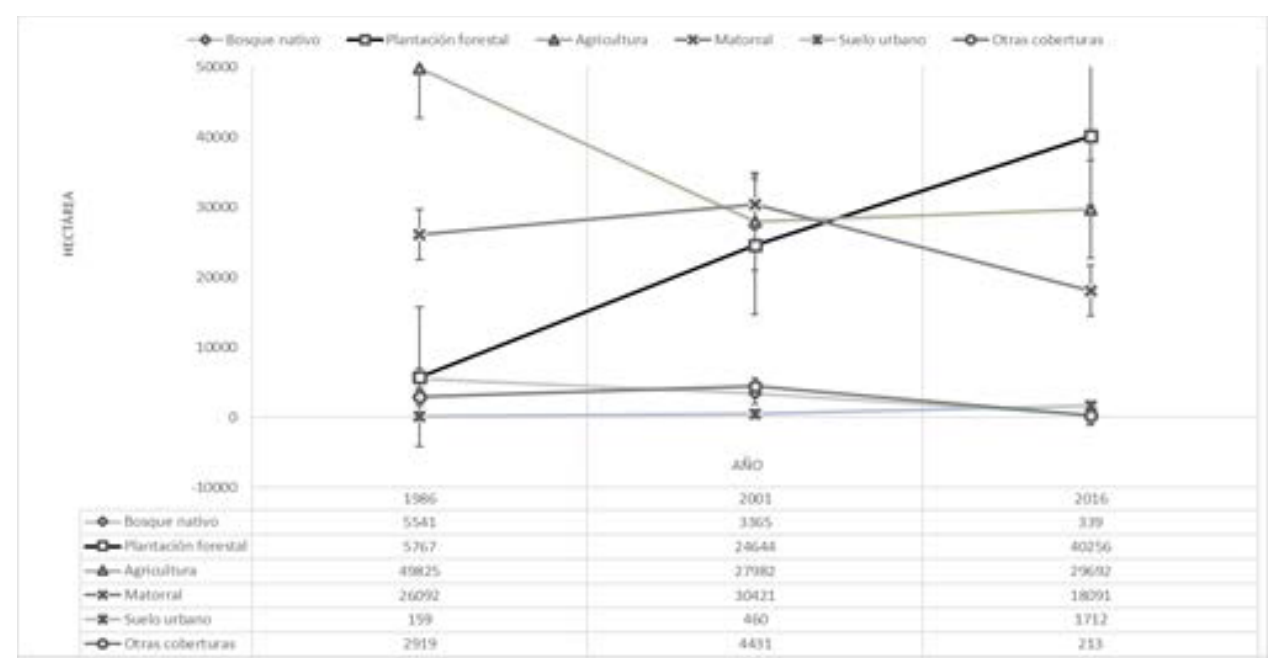

Figura 3. Trayectoria de las coberturas de bosque nativo, plantaciones forestales, suelos agrícolas y suelo urbano en los años 1986, 2001 y 2016. Las coberturas de agua, humedal y suelo descubierto han sido ingresadas como otras coberturas para facilitar la comprensión gráfica.

Fuente. Elaboración propia.

En el caso del conductor de forestación que ocupó el 58\% del total de conductores, éste se presenta de manera significativa por el proceso registrado de pérdida de suelos agrícolas, donde 17.826 hectáreas de esta cobertura, presentes en el año 1986, son forestadas para el año 2016 , contabilizando un $36 \%$ de pérdida del total de suelos agrícolas presentes en 1986. De la misma forma, otras 12.095 hectáreas de matorrales fueron forestadas entre los años 1986 a 2016.

\section{DISCUSIÓN}

\subsection{ASPECTOS METODOLÓGICOS}

La ventaja en disponer insumos tecnológicos tales como imágenes satelitales y diversos softwares de procesamiento de éstas, al igual que la disponibilidad de métodos censados para determinar cambios en las métricas del paisaje, ha sido relevante para la obtención de resultados más confiables, especialmente respecto a aquellas variables que permitieron detectar y cuantificar los cambios de uso y cobertura del suelo, que junto a la comprensión general de procesos socioambientales y políticos, vinculados como elemento incidente de transformación social, de impacto a las estructuras de paisaje y las dinámicas espaciotemporales de gran parte de la cuenca.

No obstante, se observó la necesidad de disponer de imágenes satelitales o aéreas anteriores al año 1986 que pudiesen cuantificar la dinámica en que fue interactuando y cambiando el paisaje en un proceso "Inicial". Proceso que requiere remontarnos a finales del siglo XIX, donde se registra a priori, la primera transformación del paisaje, "con la habilitación de terrenos agrícolas a expensas de la tala o quema de vegetación nativa" (Sanhueza y Azócar, 2000 como se cita en Aguayo et al. (2009), donde grandes superficies de trigo reemplazaron al bosque nativo, situación que fue incrementada por el auge de la "Fiebre del oro", período que surgió en 1848 en la costa Oeste de los Estados Unidos y en Australia, donde 
el mineral dorado produjo una masiva migración hacia lugares que en el pasado se encontraban deshabitados. De estos lugares se comenzó a demandar gran cantidad de productos como harina y trigo para su creciente población atraída por el oro, siendo Chile uno de los países que vio la oportunidad de exportar materias primas y productos agrícolas (Memoria chilena, 20191.

\subsection{DINÁMICA DEL PAISAJE}

La dinámica en que se presentan las principales fuerzas transformadoras del paisaje para la zona Centro Sur de Chile concuerda con las observadas por otros autores como: Lara y Donoso, 1996; Cisterna et al. (1999); Sanhueza y Azócar (2000); Aguayo et al. (2009), etc., los cuales indican una transformación inicial en la cobertura de bosque nativo, que es habilitado a favor de la creciente industria agropecuaria. Ya desde 1986 se observa un descenso del suelo agrícola, que para el año 2001 registra una pérdida de 21.843 hectáreas de las cuales el $36 \%$ es ganado por la cobertura de plantación forestal, seguido de un $6 \%$ y $2 \%$ de ganancia entre matorrales y suelo urbano.

De las pérdidas registradas por el suelo agrícola se observa una relación inversa con las ganancias registradas por las plantaciones forestales, las que aumentaron un $37 \%$ de superficie, pasando de 5.767 hectáreas en 1986 a 24.644 hectáreas en 2001.

De manera contraria, el aumento de superficie por parte de las plantaciones forestales se explica, en parte, con la implementación del modelo forestal a partir del año 1974 a través del Decreto Ley (DL) N 701 , que nace con el objetivo de incentivar la forestación y regular la corta o explotación de bosques nativos y plantaciones en terrenos de aptitud preferentemente forestal. Dicho DL ha tenido distintas modificaciones en el tiempo.

Para la década de los 80's Contreras (1986) señala que: "la región del Biobío es una zona forestal que se sustenta en el hecho de que el 53\% de sus tierras productivas son de aptitud exclusivamente forestal (...), donde el 38\% corresponde a terrenos de praderas con problemas de erosión que se están utilizando en forma progresiva para el cultivo de árboles maderables", especialmente en plantaciones de pino y eucaliptus.

Ya en el año 1995 el Decreto Ley (DL) No 701 se modifica con el objetivo de "Prorrogar el régimen de las bonificaciones por forestación y manejo hasta el año 2011 , orientando éstas a suelos degradados y a los pequeños propietarios forestales" (Gallardo 2013). En la actualidad Gysling y Soto (2016) observan que el 63,7\% del PIB forestal total del país se concentra en actividades de silvicultura y extracción y procesamiento de madera, celulosa y papel" A nivel de rubros, las industrias de aserrío, tableros y chapas, y de postes y polines se basan casi exclusivamente en el pino radiata, mientras que las astillas se fabrican básicamente a partir de eucaliptos (Instituto forestal, 2019).

En consecuencia, el DL $N^{\circ} 701$ directa o indirectamente, fue un argumento legal para el fomento y expansión forestal provocando en algunos casos la sustitución de bosque nativo $y$, en otros, cambios de cobertura de suelo agrícola y también la conversión de aquellos suelos con presencia de matorral o suelos considerados improductivos, lo que respalda el aumento significativo de 
las plantaciones forestales entre los años 1986 a 2001.Por su parte, los suelos agrícolas registran entre 2001 y 2016 , un ligero aumento de 1.710 hectáreas, de las cuales el $21 \%$ ocurre a expensas de la perdida de Matorrales y un $14 \%$ a costa de suelos descubiertos.

Durante este periodo, el Estado chileno venía apoyando a los propietarios agrícolas con la implementación de distintos programas de incentivos económicos destinados a la recuperación de suelos degradados, inversión tecnológica y asistencia técnica. Por su parte, los suelos forestales aumentan significativamente su superficie, registrando un incremento del 63\% entre 2001 y 2016 y del 598\% entre 1986 a 2016, incremento que es tratado por León-Muñoz et al. (2017), registrando en las cuencas de la zona Centro y Sur de Chile un incremento de la cobertura de plantaciones forestales, estableciendo el año 2011 como el año de mayor aumento en tal cobertura, la cual aumenta a expensas de una reducción de suelos cubiertos por matorrales, bosque nativo y suelos agrícolas.

Respecto al bosque nativo, este registró una pérdida del 93\% de su superficie, de la cual el 70\% corresponde a ganancias por parte de plantaciones forestales y el 16\% a suelos agrícolas. En sentido contrario, lossuelos urbanos aumentan un $977 \%$, situación que ocurre durante la década del 60' y 70', donde se acrecentaron diversos procesos transformadores del paisaje, tales como: la implementación, en el año 1965, del "Ministerio de vivienda y urbanismo" MINVU, que "impulsó políticas en materia de crecimiento urbano de las principales ciudades de la zona CentroSur de Chile" (Gross 1994), situación que se vio reflejada en importantes procesos migratorios del campesinado, los cuales, según Camus y Hajek (1998), fueron estimulados por la "política pública de sustitución de importaciones" , convirtiendo a las ciudades en focos de atracción de mano de obra. A favor de aquello diversos autores como Henríquez et al. (2006), Azócar et al. (2007) y Aguayo et al. (2009) indican que la mayoría de las ciudades chilenas se han emplazado sobre áreas de alta productividad agropecuaria.

Finalmente, es posible comprender que los principales cambios del paisaje obedecen a procesos de transformación ligados a la implementación de los modelos agrícola y forestal, modelos que a su vez interactúan y permean sobre cambios en otras coberturas, tales como el matorral y los suelos descubiertos. A la par de esto ocurren en el territorio fenómenos ligados al crecimiento de los principales asentamientos humanos y una pérdida progresiva del bosque nativo. 


\section{REFERENCIAS BIBLOGRÁFICAS}

Aguayo, M. Pauchard, A. Azócar, G. y Parra, O. (2009). Cambio del uso del suelo en el centro Sur de Chile a fines del siglo XX: Entendiendo la dinámica espacial y temporal del paisaje, Revista chilena de historia natural, Vol. LXXXII, Núm. 3, Santiago, Chile, pp. 361-374, SSN 0716-078X.

Albear, C. Tobar, B. y Vidal, A. (2018). Migración campo-ciudad: Primera mitad del siglo XX. Curicó, Universidad Católica del Maule, pp. 9, [En Línea] [Fecha de consulta 3 de enero 2019]. Disponible en: https://www.academia. edu/3677670 1/Migraci\%C3\%B3n_ campociudad_Primera_mitad_del_siglo_ XX_Mecononomics, Vol. XV, núm. 6, octubre, 635-660.

Altamirano, A. Echeverría, C. y Lara, A. (2007). Efecto de la fragmentación forestal sobre la estructura vegetacional de las poblaciones amenazadas de Legrandia concinna (Myrtaceae) del centro-sur de Chile. Revista Chilena de Historia Natural, Vol. IXXX, Núm. 1, 27-42, ISSN. 0716$078 x$

Azocar, G. Romero, H. Sanhueza, R. Vega, C. Aguayo, M. y Dolores, M. (2007). Urbanization patterns and their impacts on social restructuring of urban space in Chilean mid-cities: The case of Los Angeles, Central Chile. Land Use Policy, Vol. XXIV, ISSUE. 1, 199-2 11 . ISSN 0264-8377.

Barbier, E. Burgess, J. y Grainger, A. (2010). The forest transition: Towards a more comprehensive theoretical framework. Land Use Policy, Vol. XXVII, Núm. 2, 98-107
Camus, P. Y Hajek, E. (1999). Historia Ambiental de Chile. Descripción general de períodos en la historia ambiental y 15 estudios de casos de conflictos ambientales, Santiago de Chile, 183. ISBN 956-288091-5.

Cisterna, M. Martinez, P. Oyarzon, C. y Debels, P. (1999). Caracterización del proceso de reemplazo de vegetación nativa por plantaciones forestales en la cuenca lacustre de la cordillera de Nahuelbuta, VIII región, Chile. Revista chilena de historia natural, Vol. LXXII, mayo- septiembre, 66 1667.

Contreras, R. (1989). Región del Biobío: Actividad forestal; Grupos económicos y capital transaccional (Una contribución regional al desarrollo de la democracia), Revista Periferia, Vol. I, Núm. 1, octubre, Santiago de Chile, pp. 38. [En Línea] [Fecha de consulta 3 de enero 2019]. Disponible en http://www.memoriachilena.gob.cl/ archivos2/pdfs/MC0005679.pdf

Corporación Nacional Forestal (Conaf). Comisión Nacional de Medio Ambiente (Conama). Y Banco Internacional de Reconstrucción y Fomento (BIRF). 1999. Catastro y evaluación de los recursos vegetacionales nativos de Chile. Informe nacional con variables ambientales, Vol. I, Núm. 1, marzo. Santiago de Chile. 1999, 89.

Donoso, P. y Otero, L. (2005). Hacia una definición de país forestal: ¿Dónde se sitúa Chile?, Revista Bosque, Vol. XXVI, Núm. 3, pp. 5-18, [En Línea] [Fecha de consulta 3 de enero 2019]. Disponible en https:// scielo. conicyt.cl/scielo. php? script=sci_ xt\&pid=S07 17-92002005000300002. 
Echevarría, C., Coomes, D., Salas, J., ReyBenayas, J., Lara, A., y Newton, A. (2006). Rapid deforestation and fragmentation of Chilean Temperate Forests. Biological Conservation, 130(4), 481-494.

Foley, J., Defries, R., Asner, G., Barford, C., Bonan, G. (2005). Global consequences of land use. Science, 309/11), 570-744.

Gallardo Gallardo, E. (2013). Manual de Derecho Forestal, Corporación Nacional Forestal (CONAF), Santiago de Chile 1, 265

González, L., Mardones, M., Silva, A., Campos, E. (1999). Hidrogeoquímica y comportamiento del agua subterránea en subterránea en la cuenca del río Claro, Región del Biobío, Chile. Revista geológica de Chile. 26(2), 12.

Gross, P. (1993). Bases para la futura planificación de la ciudad chilena. Revista Eure, 59, 1-7.

Henríquez, C., Azócar, G., Aguayo, M. (2006). Cambio de uso del suelo y escorrentía superficial: aplicación de un modelo de simulación espacial en Los Ángeles, VIII Región del Biobío, Chile. Revista de Geografía Norte Grande, 36, $61-74$.

Hooke, R., Martín-Duque, J. (2012). Land transformation by humans: A review. Geological Society of America, 22(12), 4-10.

Instituto Forestal (2019). Estadísticas forestales. Recuperado de https://wef. infor.cl/bannerdestacados/2019/075/ destacado_75.php

Inzunza Bustos, J. (2010). Meteorología Descriptiva. Climas de Chile. Universidad de Concepción. Recuperado de
http://nimbus.com.uy/weather/Cursos/ Curso_2006/Textos\%20complementarios/ Meteorologia\%20descriptiva_Inzunza/ cap 15_Inzunza_Climas\%20de\%20Chile.pdf

Lara, A., Donoso, C., Aravena, J. (1996). La conservación del bosque nativo en Chile: Problemas y desafíos. Ecología de los bosques nativos de Chile (Armesto, J; Villagrán, C., Arroyo, M. eds). Editorial Universitaria, Santiago de Chile, 335-362.

León-Muñoz, J., Echeverría, C., Fuentes, R., Aburto, F. (2017). How is the land use-cover changing in drinking water catchments in the coastal range of south-central Chile $135^{\circ}$. 38.5 Sl?. Revista Bosque, 39(11, 203-209.

Auge cerealero (2019). Memoria Chilena. Biblioteca Nacional de Chile. Recuperado de http://www.memoriachilena.gob. cl/602/w3-article-9778 1.html

Pauchard, A., Aguayo, M., Peña, E., Urrutia, R. (2006). Múltiple effects of urbanization on the biodiversity of developing countries: The case of a fast-growing metropolitanárea (Concepción, Chile). Biological Conservation, 127(3), 272-281.

Ramankutty, N., Foley, J. (1999). Estimating historical changes in global land cover: Croplands from 1700 to 1992. Global Biogeochemical Cycles, 13, 997-1027.

Reyes, H., Aguilar, M., Aguirre, J., Trejo, I. (2006). Cambios en la cubierta vegetal y uso del suelo en el área del proyecto PujalCoy, San Luis Potosí, México, 1973-2000. Investigaciones Geográficas, 59, 26-42.

Sánchez, F., Hernández, H. (2018). Impactos por cambio de uso de suelo en áreas naturales protegidas de la región central de la Sierra Madre Oriental. Ciencia UAT, 12(2), 6-2 1 
Sitch, S., Friedlingstein, P., Gruber, N., Jones, por los cambios económicos de la S., Murray-Tartarolo, G., Ahlstrom, A., Doney, segunda mitad del siglo XIX; provincia S.C., Graven, H., Heinze, C., Huntingford, de Concepción. Revista Geográfica de C., Levis, S., Levy, P., Lomas, M., Poulter, B., Chile Terra Australis, 65(1), 181-194. Viory, N., Zaehle, S., Zenge, N., Arneth, A., Bonan, G., Boop, L., Canadell, J., Chevallier, Servicio Nacional de Geología y F., Ciais, P., Ellis, R., Gloor, M., Peylin, P., Minería (2003). Mapa geológico de Piao, S., Le Quéré, C., Smith, B., Zhu, B., Chile. Recuperado de http://www. Myneni, R. (2015). Recent trends and drivers ipgp.fr/ dechabal/Geol-millon.pdf of regional sources and sinks of carbon dioxide. Biogeosciences, 12(3), 653-679.

Sotelo, O., Chichia, J., Sorani, V., Flores, A. (2015). Cambios en la Vitousek, P., Mooney, H., Lubchenco, J., dinámica de deforestación de la Melillo, J. (1997). Human Domination of subcuenca de un río en México: la Eath's Ecosystems. Science, 277, 1-7.

Sanhueza, R., Azócar, G. (2000). Transformaciones ambientales provocadas Norte Grande, 1(61), 221-227. imposibilidad de recuperación de los hábitats originales después del cese de la deforestación. Revista de Geografía 